Article

\title{
Research on the Fault Characteristic of Wind Turbine Generator System Considering the Spatiotemporal Distribution of the Actual Wind Speed
}

\author{
Xiaoling Sheng *, Shuting Wan *, Kanru Cheng and Xuan Wang \\ School of Energy Power and Mechanical Engineering, North China Electric Power University, Baoding 071003, \\ China; 2172224057@ncepu.edu.cn (K.C.); 2182224004@ncepu.edu.cn (X.W.) \\ * Correspondence: 52451712@ncepu.edu.cn (X.S.); 52450809@ncepu.edu.cn (S.W.); \\ Tel.: +86-1365-312-3501 (X.S.); +86-1358-299-6591 (S.W.)
}

Received: 29 October 2019; Accepted: 7 January 2020; Published: 10 January 2020

\begin{abstract}
A reliable fault monitoring system is one of the conditions that must be considered in the design of large wind farms today. The most important factor for the fault monitoring should be the accurate diagnosis criteria with sensitive fault characteristics. Most of the current fault diagnosis criteria are obtained based on the average wind speed at the center of the hub which is not in accord with the actual wind condition in nature. So, this paper utilizes an equivalent wind speed (EWS), which can describe the actual wind speed spatiotemporal distribution on the rotor disk area considering the effects of wind shear and tower shadow, to analyze the common mechanical and electrical faults again. Firstly, the EWS model applicable to the 3-blade wind turbines is introduced; then the new fault characteristics of the wind turbine rotor aerodynamic imbalance and the stator winding asymmetry are theoretically analyzed based on the EWS model; finally, the simulation platform is built in Matlab/Simulink for comparison and the simulation result is well consistent with the theory analysis. The aim of this research is to find more accurate fault characteristics and help promoting the healthy development of wind power industry.
\end{abstract}

Keywords: wind turbines; equivalent wind speed; rotor aerodynamic imbalance; stator winding asymmetry; fault characteristics

\section{Introduction}

With the development of wind turbines (WT) in the direction of large-scale, the towers are getting higher and higher, and the blade radius is getting longer and longer, which makes the influence of wind shear and tower shadow effects on the aerodynamic load of the WT more obvious. Wind shear describes the variation in wind speed with vertical elevation, whereas tower shadow reflects the reassignment of wind speed due to the presence of a tower. Due to the factors such as wind shear and tower shadow, the actual wind speed is different everywhere on the rotor disk area, and the difference will change greatly with the WT geometry such as the blade radius and the tower outer diameter, as well as the vegetation and other geography [1]. Therefore, the wind speed in nature has been changing with time and space, which can be called the spatiotemporal distribution characteristic of wind speed.

As shown in Figure 1, an anemometer is usually installed near the hub center point $O$ to detect the real-time wind speed, and then the average value over a period of time is taken as the average wind speed (AWS) at the center of the hub. However, the wind speed at this point does not completely reflect the wind speed on the whole rotor disk area. In particular, the rotor dimension of the modern WT is very large, and the wind speed differs across the rotor disk area and changes randomly. Thus, the wind turbine drive torque, the pitch bending moment, and the yaw moment, and so on, will change 
accordingly. The wind speed spatiotemporal distribution characteristics directly affect the aerodynamic load resulting in load fluctuation of the WT [2-4]. Besides, it will also affect the power output of the wind turbine generator system (WTGS) [1,5-7]. The influence of wind shear and tower shadow effects on power in terms of power fluctuation [1], power loss [5], and average output power [6] have been investigated in detail and a frequency domain approach for evaluating the impact of tower shadow and wind shear on the tie-line power oscillations was described in [7]. They concluded that both wind shear and tower shadow were sources of periodic power fluctuations and average power loss.

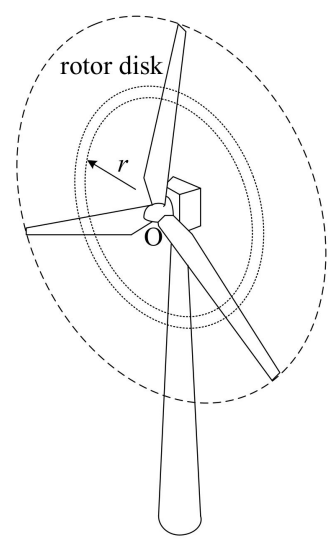

Figure 1. Wind turbine schematic diagram.

From the above researches, it can be inferred that the WTGS fault characteristic may be influenced by wind speed spatiotemporal distribution condition. However, this problem is seldom discussed in previous studies. In [8], the impact of blade mass imbalance fault on the power characteristics of a doubly-fed induction generator (DFIG) was analyzed considering the effects of wind shear and tower shadow. In [9], the influence factors causing voltage flicker of WTGS were analyzed, including wind shear, tower shadow, gearbox tooth, and blade break down. And a classifier algorithm which can detect different causes of flicker was proposed. In [10], the torque and vibration characteristics of the wind turbines drive train during voltage dips were investigated considering the wind shear and tower shadow effects. The other similar researches about this topic are truly seldom reported by now.

Currently, most of the mechanical and electrical fault diagnoses for WT with DFIG are usually based on the average wind speed at the center of the hub. Since the spatiotemporal distribution of wind speed is not considered, it may cause the analytical method or the diagnosis result to deviate from the actual situation, thus affecting the accuracy of the diagnosis. In order to better understand the fault characteristics on the condition of the actual wind speed considering the spatiotemporal distribution, two faults are selected from the common mechanical and electrical faults of the WTGS for comparative analysis. These two faults are the rotor aerodynamic imbalance of WT and the stator winding asymmetry fault of DFIG.

Aerodynamic imbalance means the aerodynamic torques of the three blades are unevenly distributed, which is different from the blade mass imbalance in [8]. The reason may be a pitch angle difference among the three blades, caused by manufacturing or control errors, or blade airfoil changes due to icing on the blade and other factors. Aerodynamic imbalance can cause the main shaft vibration and further aggravate the fatigue of the blade, bearing, gear, and other parts. At present, the aerodynamic imbalance fault study is mainly focused on two aspects. The first is to analyze the vibration characteristics of the WT to diagnose the aerodynamic imbalance fault [11,12], and the second is to study the electrical characteristics under the aerodynamic imbalance fault [13,14]. These researches on the aerodynamic imbalance fault are mostly based on the AWS at the hub center, and the spatiotemporal distribution characteristics of the actual wind speed are less considered.

It is reported that about $38 \%$ of the WTGS faults are related to the stator according to the failure statistics [15], and the stator faults is very critical because its important role in the WTGS. To avoid 
severe damage to stator and the WTGS, the early fault detecting such as the winding asymmetry and resistance variations may have important significance. Because the early fault characteristic is little evident, the diagnostic accuracy becomes very important. Stefani et al. $[16,17]$ researched on the stator winding asymmetrical fault based on the frequency analysis of the rotor modulating signals. Dai [18] used the modified Hilbert-Huang Transform method to analyze the stator current in order to make the fault characteristics more obvious. Williamson et al. [19] derived simple expressions for the frequencies of the harmonic components in the steady state stator line current of a DFIG operating under various conditions of winding asymmetry. These studies have helped us understand the characteristics of stator winding asymmetry faults. However, they do not consider the spatiotemporal distribution of actual wind speed. Although Gritli et al. [20] researched the stator winding fault by using wavelet analysis under time-varying conditions, the wind shear and tower shadow were not considered.

A wind speed model named equivalent wind speed (EWS) considering the effects of wind shear and tower shadow is established in our researches [21,22] based on the relevant researches [23-25]. However, these researches only study the establishment of the wind speed model. The rear drive trains system, the generator and the control system are not taken into account in these researches. To this end, the EWS model is added to the DFIG and its control system, and a complete WTGS model with DFIG is built in this paper. Then the influence of the EWS on the mechanical and electrical fault of the WTGS is studied. Since the motor current signature analysis (MCSA) method is widely used and easier to measure, the DFIG current characteristics of the faults are analyzed mainly in the paper. The main objective of the research is to provide theoretical support for optimizing the fault monitoring system of the WTGS in the future.

\section{Equivalent Wind Speed}

Considering the effects of wind shear and tower shadow, the EWS of the 3-blade WT can be expressed as the sum of the average wind speed at the hub, the wind shear component and the tower shadow component:

$$
V_{\mathrm{eq}}=V_{\mathrm{H}}+V_{\mathrm{ws}}+V_{\mathrm{ts}}
$$

where $V_{\text {eq }}$ is the equivalent wind speed $(\mathrm{m} / \mathrm{s}) ; V_{\mathrm{H}}$ is the wind speed at the height of hub center $(\mathrm{m} / \mathrm{s})$; $V_{\text {ws }}$ is the wind shear fluctuation component $(\mathrm{m} / \mathrm{s})$; and $V_{\mathrm{ts}}$ is the tower shadow fluctuation component $(\mathrm{m} / \mathrm{s})$.

According to the former research basis, the expression corresponding to the $V_{\mathrm{ws}}$ and $V_{\mathrm{ts}}$ can be respectively expanded as [21-23]:

$$
\begin{gathered}
V_{\mathrm{ws}}=V_{\mathrm{H}}\left[\frac{\alpha(\alpha-1)}{8}\left(\frac{r}{H}\right)^{2}+\frac{\alpha(\alpha-1)(\alpha-2)}{60}\left(\frac{r}{H}\right)^{3} \cos 3 \beta+\frac{\alpha(\alpha-1)(\alpha-2)(\alpha-3)}{576}\left(\frac{r}{H}\right)^{4} \cos 4 \beta\right] \\
V_{\mathrm{ts}}=\frac{M V_{H}}{3 R^{2}} \sum_{b=1}^{3}\left[\frac{A^{2}}{\sin ^{2} \beta_{b}} \ln \frac{R^{2} \sin ^{2} \beta_{b}+x^{2}}{x^{2}}-\frac{2 A^{2} R^{2}}{R^{2} \sin ^{2} \beta_{b}+x^{2}}\right] \\
\beta_{1}=\beta \beta_{2}=\beta_{1}+\frac{2 \pi}{3} \beta_{3}=\beta_{1}+\frac{4 \pi}{3} \\
M=1+\frac{\alpha(\alpha-1) R^{2}}{8 H^{2}}
\end{gathered}
$$

where $R$ is the blade radius $(\mathrm{m}) ; r$ is the distance from the blade element to the hub center $(\mathrm{m})$, as shown in Figure 1, range from 0 to $R ; H$ is the hub height (m); $\alpha$ is the wind shear exponent; $A$ is the tower radius $(\mathrm{m}) ; x$ is the distance from the rotor disk plane to the tower center line $(\mathrm{m}) ; \beta$ is the azimuth angle (rad); $\beta_{\mathrm{b}}(\mathrm{b}=1,2,3)$ is the azimuth angle corresponding to the three blades (rad), and $\beta_{1}=\beta, \beta_{2}=$ $\beta_{1}+2 \pi / 3, \beta_{3}=\beta_{1}+4 \pi / 3$.

Substitute the Equations (2) and (3) into (1) and extract $V_{\mathrm{H}}$ from the Equations, and we can get the EWS expressions as follows:

$$
V_{\mathrm{eq}}=W_{\mathrm{eq}} V_{\mathrm{H}}
$$




$$
\begin{aligned}
W_{\mathrm{eq}} & =1+\left[\frac{\alpha(\alpha-1)}{8}\left(\frac{r}{H}\right)^{2}+\frac{\alpha(\alpha-1)(\alpha-2)}{60}\left(\frac{r}{H}\right)^{3} \cos 3 \beta+\frac{\alpha(\alpha-1)(\alpha-2)(\alpha-3)}{576}\left(\frac{r}{H}\right)^{4} \cos 4 \beta\right] \\
& +\frac{M}{3 R^{2}} \sum_{b=1}^{3}\left[\frac{A^{2}}{\sin ^{2} \beta_{b}} \ln \frac{R^{2} \sin ^{2} \beta_{b}+x^{2}}{x^{2}}-\frac{2 A^{2} R^{2}}{R^{2} \sin ^{2} \beta_{b}+x^{2}}\right]
\end{aligned}
$$

$W_{\text {eq }}$ can be called the equivalent wind speed transform coefficient. The EWS model established by Equations (5) and (6) can calculate the wind speed value at any point on the entire rotor disk area. It is an accurate and practical wind speed calculation model. Applying it to the study of the fault diagnosis, it can reflect the wind load conditions of the WT and the fault characteristics.

According to the parameters of a 3-blade 1.5 MW WT, the distribution map of the equivalent wind speed transform coefficient is plotted, as shown in Figure 2. It can be seen from the figure that due to the effects of wind shear and tower shadow, the wind speed on the rotor disk area is not uniform, and there is obvious periodic fluctuation on the time axis, and the main frequency is three times of the rotor rotating frequency.

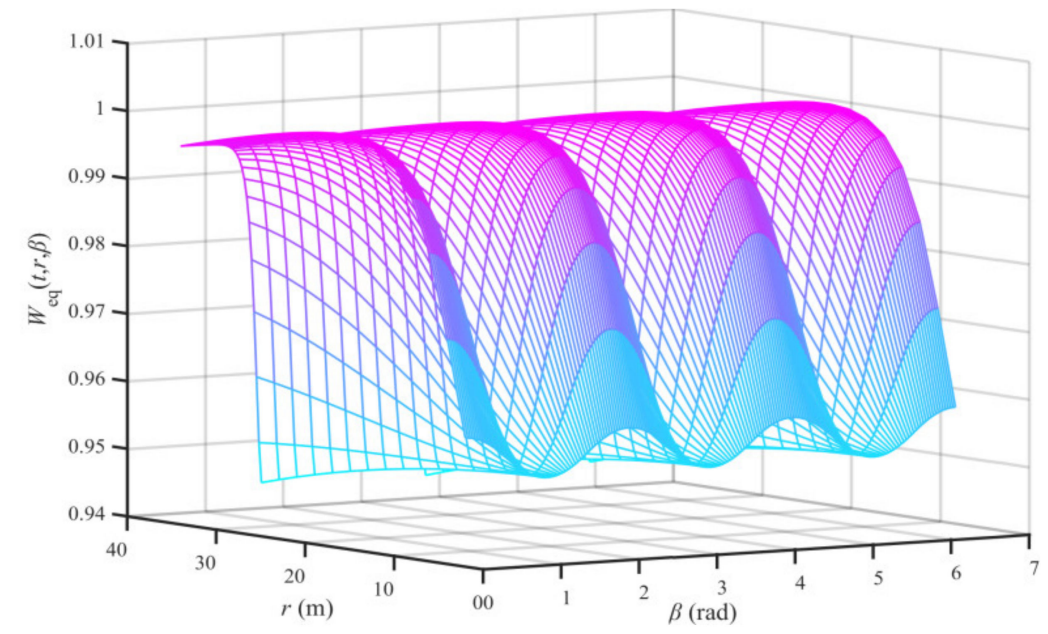

Figure 2. Equivalent wind speed transform coefficient $W_{\text {eq }}$.

In order to facilitate the subsequent analysis, the EWS calculation equation is simplified, and the Fourier fitting is performed on the EWS curve corresponding to the WT whose blade radius is $35 \mathrm{~m}$, and $V_{\mathrm{H}}$ is $11 \mathrm{~m} / \mathrm{s}$. The fitting curve and the original EWS curve are shown in Figure 3.

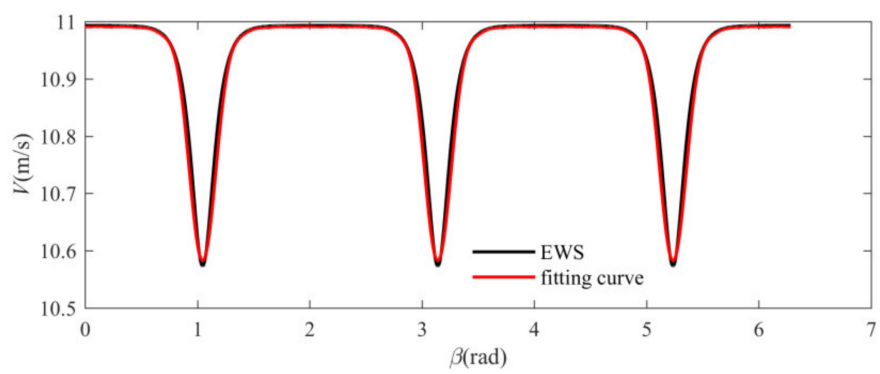

Figure 3. Original equivalent wind speed curve and the fitting curve.

The fitting curve is highly coincident with the original EWS curve, and the equation corresponding to the fitting curve is:

$$
V=a_{0}+a_{1} \cos (\omega t)+a_{2} \cos (2 \omega t)+\ldots \ldots+a_{k} \cos (k \omega t) k=1,2,3 \ldots
$$

The equation of the fitting curve contains only the constant term and the trigonometric term, where the constant term $a_{0}$ is close to the hub average wind speed $V_{\mathrm{H}}=11 \mathrm{~m} / \mathrm{s}$; the $\omega$ in trigonometric 
term has a value of 9.42 , which is close to three times of the rotor rotating angular frequency $\left(3 \omega_{\mathrm{w}}\right)$, so the trigonometric term can be written as $\cos \left(3 k \omega_{\mathrm{w}} t\right)$, and the more the number of trigonometric terms, the higher the fitting accuracy of the fitted curve and the original curve. In the above figure, when the number of trigonometric terms reaches 8 , the fitting accuracy has reached 0.99 . The Fourier fitting is also performed on the other EWS curve corresponding to the WT of different parameters, which is basically consistent with the above conclusion, but the number of trigonometric terms should be adjusted according to the actual situation. Therefore, $V_{\text {eq }}$ can be approximated as:

$$
V_{\mathrm{eq}}=V_{\mathrm{H}}+\sum_{k=1}^{n} V_{k} \cos \left(3 k \omega_{\mathrm{w}} t+\phi_{k}\right)
$$

where $V_{k}$ and $\varphi_{k}$ are respectively the amplitudes $(\mathrm{m} / \mathrm{s})$ and the phase angles (rad) corresponding to the $k$-th trigonometric term; and $\omega_{\mathrm{w}}$ is the rotor rotating angular frequency ( $\left.\mathrm{rad} / \mathrm{s}\right)$.

The Equation (8) is only used to facilitate the following analysis, and the final simulation adopts the Equations (1)-(6) to build the equivalent wind speed model.

According to the wind turbine aerodynamics theory, there is a proportional relationship between the mechanical torque output by the wind turbine and the quadratic wind speed. So, combining the Equation (8), the output mechanical torque $T_{\mathrm{m}}$ can be obtained as follows:

$$
T_{\mathrm{m}}=T_{\mathrm{m} 0}+\frac{2 T_{\mathrm{m} 0}}{V_{\mathrm{H}}} \sum_{k=1}^{n} V_{k} \cos \left(3 k \omega_{\mathrm{w}} t+\phi_{k}\right)+\frac{T_{\mathrm{m} 0}}{V_{\mathrm{H}}^{2}}\left[\sum_{k=1}^{n} V_{k} \cos \left(3 k \omega_{\mathrm{w}} t+\phi_{k}\right)\right]^{2}
$$

where $T_{\mathrm{m} 0}$ is the fundamental component of aerodynamic torque $(\mathrm{N} \cdot \mathrm{m}) ; T_{\mathrm{m} 0}=0.5 \rho \pi R^{3} C_{\mathrm{p}} V_{\mathrm{H}}^{2} / \lambda ; \rho$ is the air density $\left(\mathrm{kg} / \mathrm{m}^{3}\right) ; C_{\mathrm{p}}$ is the optimum power coefficient; and $\lambda$ is the optimum tip speed ratio.

The third term in Equation (9) is also a polynomial containing $\cos \left(3 k \omega_{\mathrm{w}} t\right)$ after expansion. Then the expression of the mechanical torque obtained by combining the second and third terms is:

$$
T_{\mathrm{m}}=T_{\mathrm{m} 0}+\sum_{k=1}^{n} T_{k} \cos \left(3 k \omega_{\mathrm{w}} t+\phi_{k}\right)
$$

where $T_{k}$ and $\phi_{k}$ are respectively the amplitudes $(\mathrm{N} \cdot \mathrm{m})$ and the phase angles (rad) of the torque oscillation components caused by the effects of wind shear and tower shadow in the EWS.

\section{Rotor Aerodynamic Imbalance and Stator Winding Asymmetry}

Taking two common faults as example, this paper focuses on analyzing the different points of fault characteristics under different wind conditions of EWS and AWS, so that we can grasp the influence of EWS on the mechanical and electrical fault characteristics.

\subsection{Rotor Aerodynamic Imbalance}

Based on the analysis above mentioned and the Reference [13], the mechanical torque under the rotor aerodynamic imbalance and EWS can be expressed as (omitting the initial phase angle):

$$
T_{\mathrm{m}}=\left(T_{\mathrm{m} 0}-T_{\mathrm{im}}\right)+\sum_{k=1}^{n} T_{k} \cos \left(3 k \omega_{\mathrm{w}} t\right)+T_{\mathrm{a}} \cos \left(\omega_{\mathrm{w}} t\right)
$$

where $T_{\mathrm{im}}$ is the constant variation caused by aerodynamic imbalance $(\mathrm{N} \cdot \mathrm{m})$; and $T_{\mathrm{a}}$ is the amplitude of the torque oscillation components caused by aerodynamic imbalance $(\mathrm{N} \cdot \mathrm{m})$. 
For the convenience of calculation, the above mechanical torque is simplified as follows:

$$
\left\{\begin{array}{l}
T_{\mathrm{m}}=\left(T_{\mathrm{m} 0}-T_{\mathrm{im}}\right)+\sum_{k=1}^{n+1} T_{k} \cos \left(\omega_{k} t\right) \\
\omega_{k}=3 k \omega_{\mathrm{w}} ;(k=1,2, \ldots n) \\
\omega_{n+1}=\omega_{\mathrm{w}} \\
T_{n+1}=T_{\mathrm{a}}
\end{array}\right.
$$

Then calculate the DFIG rotor electrical angular speed $\omega_{\mathrm{r}}$ according to the motion equation of the DFIG [26],

$$
\omega_{\mathrm{r}}=\frac{n_{\mathrm{p}}}{J} \int\left(T_{\mathrm{m} 0}-T_{\mathrm{im}}-T_{\mathrm{e} 0}\right) \mathrm{d} t+\frac{n_{\mathrm{p}}}{J} \int \sum_{k=1}^{n+1} T_{k} \cos \left(\omega_{k} t\right) d t=\omega_{\mathrm{r} 0}+\sum_{k=1}^{n+1} \frac{n_{\mathrm{p}} T_{k}}{J \omega_{k}} \sin \left(\omega_{k} t\right)
$$

where $T_{\mathrm{eo}}$ is the electromagnetic torque of the DFIG $(\mathrm{N} \cdot \mathrm{m}) ; n_{\mathrm{p}}$ is the pole pairs; and $J$ is the equivalent moment of inertia of the WT $\left(\mathrm{kg} \cdot \mathrm{m}^{2}\right)$.

Let $\omega_{1}$ be the angular frequency of the grid, according to the speed-frequency relationship of the DFIG, the angular frequency of the rotor current $\omega_{z}$ can be obtained:

$$
\omega_{\mathrm{z}}=\omega_{1}-\omega_{r}=\omega_{z 0}-\sum_{k=1}^{n+1} \frac{n_{\mathrm{p}} T_{k}}{J \omega_{k}} \sin \left(\omega_{k} t\right)
$$

where $\omega_{\mathrm{z} 0}=\omega_{1}-\omega_{\mathrm{r} 0}$, which is the fundamental frequency of rotor current $(\mathrm{rad} / \mathrm{s})$.

Then the DFIG rotor current $i_{\mathrm{ra}}$ under the EWS and aerodynamic imbalance can be obtained (the detailed computation process can be found in Appendix A):

$$
i_{\mathrm{ra}}=I_{\mathrm{r}} \cos \left(\omega_{\mathrm{z} 0} t\right)-\sum_{k=1}^{n} I_{k} \sin \left(\omega_{\mathrm{z} 0} t+3 k \omega_{\mathrm{w}} t\right)-\sum_{k=1}^{n} I_{k} \sin \left(\omega_{\mathrm{z} 0} t-3 k \omega_{\mathrm{w}} t\right)-I_{\mathrm{r} 1} \sin \left(\omega_{\mathrm{z} 0} t+\omega_{\mathrm{w}} t\right)-I_{\mathrm{r} 1} \sin \left(\omega_{\mathrm{z} 0} t-\omega_{\mathrm{w}} t\right)
$$

where $I_{\mathrm{r}}$ is the amplitude of rotor current fundamental wave (A); $I_{k}=I_{\mathrm{r}} n_{\mathrm{p}} T_{k} / 18 J k^{2} \omega_{\mathrm{w}}^{2} ; I_{\mathrm{r} 1}=I_{\mathrm{r}} n_{\mathrm{p}} T_{\mathrm{a}} / 2 J \omega_{\mathrm{w}}^{2}$.

As indicated in Equation (15), in addition to the fundamental current at frequency $\omega_{\mathrm{z} 0}$, there are also modulation harmonic components at the frequencies of $\omega_{\mathrm{z} 0}+3 k \omega_{\mathrm{w}}, \omega_{\mathrm{z} 0}-3 k \omega_{\mathrm{w}}, \omega_{\mathrm{z} 0}+\omega_{\mathrm{w}}$ and $\omega_{\mathrm{z} 0}-\omega_{\mathrm{w}}$ in the rotor current. In addition, it is necessary to notice that $3 k \omega_{\mathrm{w}}$ and $\omega_{\mathrm{w}}$ are the main modulation harmonic frequencies, but not only these two types of modulation frequencies in the rotor current. After these harmonics appear, frequency modulation occurs between the two kinds of harmonics, that is, new modulation frequencies appear in the current: $3 k \omega_{\mathrm{w}} \pm \omega_{\mathrm{w}}$. In the Reference [27], it is studied that in the case of mass imbalance fault, many high-frequency small-amplitude components appear in the current besides the main modulation frequency $\omega_{\mathrm{w}}$. Therefore, in the case of EWS, the harmonic component at the frequency $\omega_{\mathrm{z} 0} \pm\left(3 k \omega_{\mathrm{w}} \pm \omega_{\mathrm{w}}\right)$ in the current is composed of two parts. One part is caused by aerodynamic imbalance; the other part is caused by the modulation between $3 k \omega_{\mathrm{w}}$ and $\omega_{\mathrm{w}}$.

To obtain a steady electro-mechanical energy conversion, and keep the rotating magnetic field between the stator and rotor relatively static, there should be modulation harmonic components at the frequencies of $\omega_{1} \pm 3 k \omega_{\mathrm{w}}$ and $\omega_{1} \pm \omega_{\mathrm{w}}$ in addition to the fundamental frequency $\omega_{1}$ in the stator current. The small harmonics at the frequencies of $\omega_{1} \pm\left(3 k \omega_{\mathrm{w}} \pm \omega_{\mathrm{W}}\right)$ will also be observed on the condition of the aerodynamic imbalance fault under the EWS.

\subsection{Stator Winding Asymmetry}

First we analyze the stator winding asymmetry fault of the DFIG on the condition of constant AWS at the hub centre. Firstly, an inverse sequence component at the frequency $-\omega_{1}$ in the stator determines an inverse counter rotating magnetic field. Then the inverse sequence component produces an harmonic component in the rotor at frequency $(2-s) \omega_{1}(s$ is the slip ratio) and give rise to 
electromagnetic and mechanical interaction between stator and rotor, which determine the further harmonic components both on stator and rotor [10]. As a consequence of this interaction, the following stator current components $\omega_{\text {ss }}$ and rotor current components $\omega_{\text {sr }}$ appear:

$$
\begin{gathered}
\omega_{\mathrm{ss}}= \pm k_{1} \omega_{1}\left(k_{1}=1,3,5 \ldots\right) \\
\omega_{\mathrm{sr}}=\left(2 k_{2} \pm s\right) \omega_{1}\left(k_{2}=1,2,3 \ldots\right)
\end{gathered}
$$

Then we will analyze the stator winding asymmetry fault of the DFIG on the condition of EWS. According to the above analysis, the inverse sequence component at the frequency $-\omega_{1}$ is first generated in the stator current when the stator winding asymmetry fault occurs, and then the corresponding rotor current frequency $\omega_{\mathrm{z} 1}$ can be obtained under the EWS according to the speed-frequency relationship of the DFIG and the Equations (10) and (13):

$$
\omega_{\mathrm{z} 1}=\omega_{1}+\omega_{\mathrm{r} 0}+\sum_{k=1}^{n} \frac{n_{p} T_{k}}{3 J k \omega_{\mathrm{w}}} \sin \left(3 k \omega_{\mathrm{w}} t\right)=(2-s) \omega_{1}+\sum_{k=1}^{n} \frac{n_{p} T_{k}}{3 J k \omega_{\mathrm{w}}} \sin \left(3 k \omega_{\mathrm{w}} t\right)
$$

Then, with reference to Equation (15), we can learn that, in addition to the fault frequency $(2-s) \omega_{1}$ caused by the stator winding asymmetry, there are also harmonic frequencies $(2-s) \omega_{1} \pm 3 k \omega_{\mathrm{w}}$ caused by the EWS in the rotor current. However, the harmonic analysis is not over yet. The harmonic components in the rotor current will continue to induce harmonic at the frequency $3 \omega_{1}$ and $3 \omega_{1} \pm 3 k \omega_{\mathrm{w}}$ in the stator current. Repeatedly, the harmonics in the stator and rotor currents will continue to propagate according to this law, and finally the following harmonic frequencies in the stator and rotor currents are generated:

$$
\begin{gathered}
\omega_{\mathrm{sse}}= \pm k_{1} \omega_{1} \pm 3 k \omega_{\mathrm{w}}\left(k_{1}=1,3,5 \ldots\right) \\
\omega_{\mathrm{sre}}=\left(2 k_{2} \pm s\right) \omega_{1} \pm 3 k \omega_{\mathrm{w}}\left(k_{2}=1,2,3 \ldots\right)
\end{gathered}
$$

\section{Simulation Analysis}

In order to verify the correctness of the theoretical analysis described above, a simulation platform of 1.5 MW WTGS with DFIG is built in the MATLAB/Simulink environment (MATLAB R2017a, MathWorks Company, Natick, MA, USA). The sketch of the simulation platform is shown in Figure 4. The simulation parameters are shown in Table 1.

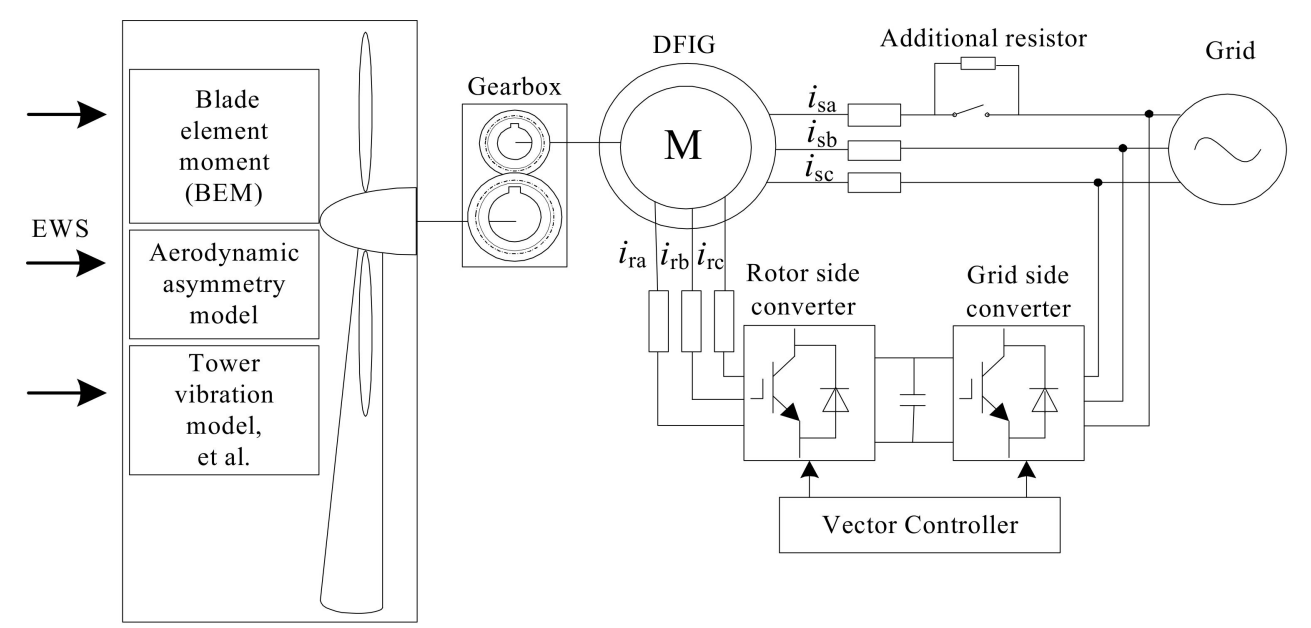

Figure 4. Simulation platform. 
Table 1. Parameters of 1.5 MW doubly-fed induction generator (DFIG) wind turbine.

\begin{tabular}{cccc}
\hline Parameters & Value & Parameters & Value \\
\hline Rated power $(\mathrm{MW})$ & 1.5 & Stator resistance (p.u.) & 0.023 \\
Rated wind speed $(\mathrm{m} / \mathrm{s})$ & 11 & Stator leakage inductance $(\mathrm{p} . \mathrm{u})$. & 0.18 \\
Optimum tip speed ratio & 10 & Rotor resistance(p.u.) & 0.016 \\
Optimum power coefficient & 0.5 & Rotor leakage inductance (p.u.) & 0.16 \\
Blade radius $(\mathrm{m})$ & 35 & Pairs of poles & 2 \\
Tower average radius $(\mathrm{m})$ & 1.7 & Inertia constant $(\mathrm{s})$ & 0.685 \\
Centre height of the hub $(\mathrm{m})$ & 70 & Air density $\left(\mathrm{kg} / \mathrm{m}^{3}\right)$ & 1.225 \\
\hline
\end{tabular}

The simulation platform mainly includes the EWS model, WT aerodynamics model, gearbox model, DFIG model, and vector control model. Among them, the WT aerodynamics model includes the blade element moment theory, the tower vibration model, and the coordinate transformation model, etc. This aerodynamics model can calculate the aerodynamic torque and other parameters of the WT output under the aerodynamic imbalance caused by the inconsistent pitch angle among three blades, and the detail can be found in our article Reference [13].

As far as the simulation of stator winding faults, two methods are usually used. One method is to simulate the stator inter-turn short circuit fault by changing the number of shorted turns, and the other is to add an additional resistor or inductor in series with the stator winding to simulate the winding asymmetry fault. Since the second method is simple and easy to implement, it is applied in many situations. For example, References [16-18,20] all adopt the second method. So, in this paper, the stator winding asymmetry fault is simulated by connecting an additional resistor in series with the stator phase A. This method is only used for the simulation of stator winding asymmetry originating from the resistance variations because of unreasonable structure design and electromagnetism thermal field, et al. The stator inter-turn short circuit fault is not considered here.

\subsection{Normal Condition Simulation}

Firstly, the simulation of normal running condition is performed under two different kinds of wind speed-AWS and EWS. The average constant wind speed at the hub centre is $12 \mathrm{~m} / \mathrm{s}$, and the rotor rotating speed in the normal condition is $30 \mathrm{r} / \mathrm{min}$ (the corresponding rotating frequency $\mathrm{P}$ is $0.5 \mathrm{~Hz}$ ). The parameters using in the EWS model are: wind shear exponent is 0.4 ; the distance from the tower middle line to the blade is $4.5 \mathrm{~m}$; tower radius is $1.7 \mathrm{~m}$; blade radius is $35 \mathrm{~m}$; the hub height is $70 \mathrm{~m}$; the wind speed at the hub centre is $12 \mathrm{~m} / \mathrm{s}$. The comparison results are shown in Figures 5-8.

Figure 5 is the fast Fourier transform (FFT) spectrum of the mechanical torque output from the WT. It can be seen from the figure that there are obvious harmonic fluctuation components in the torque due to the influence of wind shear and tower shadow effects in the EWS, and the harmonic frequencies are $1.5 \mathrm{~Hz}, 3 \mathrm{~Hz} \ldots 3 \mathrm{kP}$ ( $k$ takes positive number). Besides, the harmonic with frequency of $3 \mathrm{P}(1.5 \mathrm{~Hz})$ is the main component. Figure 6 shows the FFT spectrum of the rotor rotating speed, which has the similar result as the torque, and also has distinct harmonic components of $3 \mathrm{kP}$.

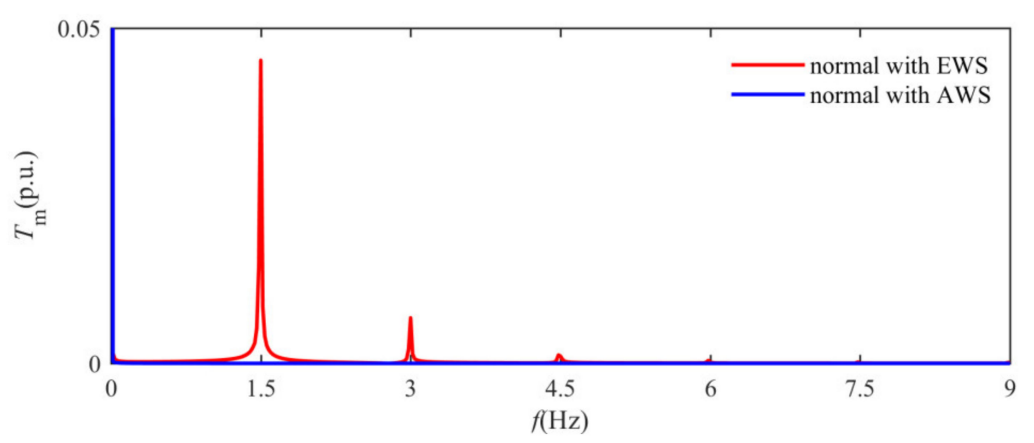

Figure 5. Fast Fourier transform (FFT) of the wind turbine (WT) mechanical torque. 


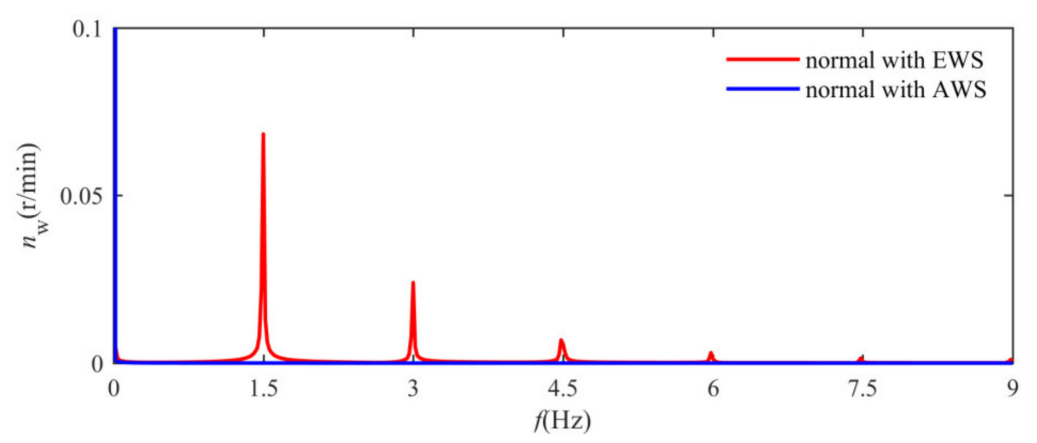

Figure 6. FFT of the WT rotor rotating speed.

Figure 7 shows the power spectral density (PSD) analysis results of the stator current. On the normal condition with EWS, there exists distinct harmonics in the stator current besides the fundamental wave. The harmonic frequencies in red line around the fundamental frequency are $50 \pm 3 k \mathrm{P}(1.5 k)$. That is to say, the modulation frequency is $3 \mathrm{kP}$ which is three times of the rotor rotating frequency. However, these harmonics are not present on the normal condition with AWS as shown in the blue line in Figure 7.

Figure 8 shows the PSD analysis results of the rotor current. Similar to the analysis of the stator current, the harmonic with modulation frequency of $3 \mathrm{kP}$ appear on both sides of the fundamental frequency $(10 \mathrm{~Hz})$ of the rotor current. However, unlike the stator current results, the rotor current harmonic amplitudes are relatively high compared with the fundamental amplitude. In the stator current, the harmonic amplitude at frequency $50+3 \mathrm{P}$ is about 0.004 p.u., which is about $0.58 \%$ of the fundamental amplitude. However, in the rotor current, the harmonic amplitude at frequency $10+$ $3 \mathrm{P}$ is about 0.0335 p.u., which is about $4.55 \%$ of the fundamental amplitude. The reason may be that the rotor side converter mainly controls the stator current, so the harmonic performance in the rotor current is relatively obvious than that of the stator current. The similar effect can be observed in the PSD spectrum. In Figure 7, the amplitude at the $51.5 \mathrm{~Hz}$ is about $-24 \mathrm{~dB}$. However, the amplitude at $11.5 \mathrm{~Hz}$ is about $-14.75 \mathrm{~dB}$ in Figure 8, which is higher than that of the stator current.

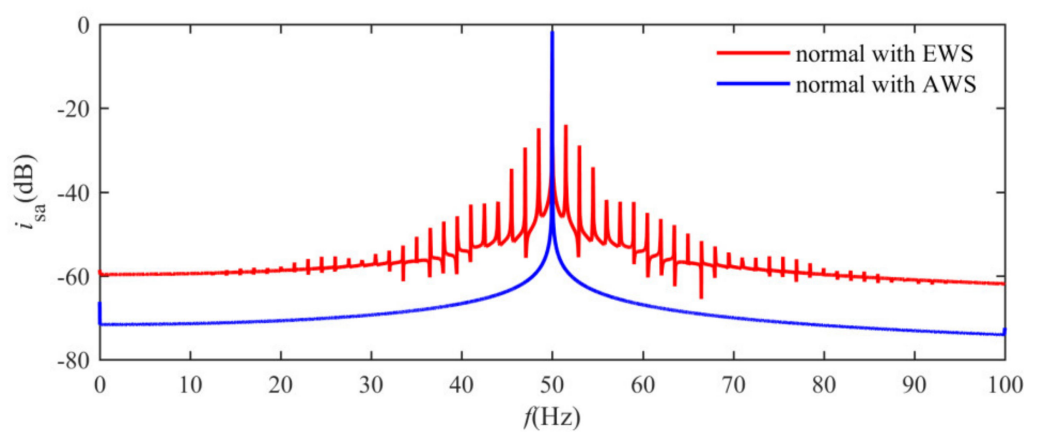

Figure 7. Stator current comparison on normal condition.

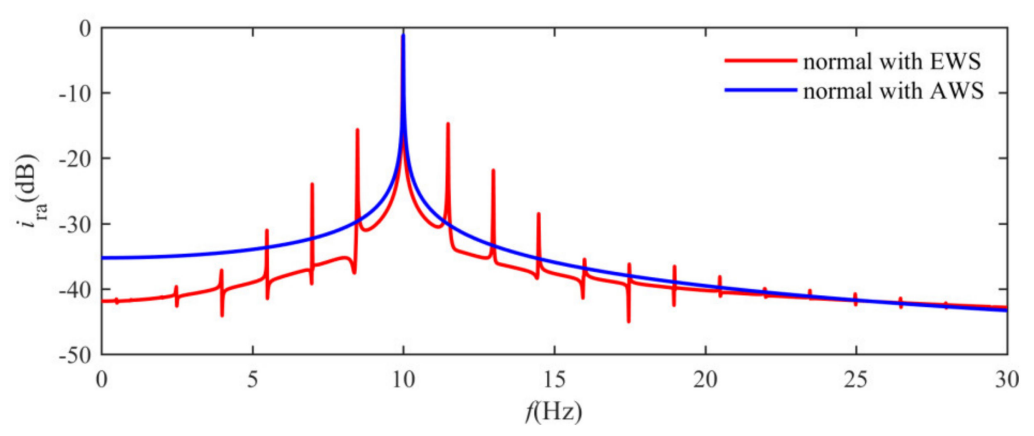

Figure 8. Rotor current comparison on normal condition. 


\subsection{Rotor Aerodynamic Imbalance Simulation}

In this part, the rotor aerodynamic imbalance simulation is performed under AWS and EWS respectively. Under each case, three aerodynamic imbalance scenarios are simulated with the pitch angle of one blade adjusted by $+1^{\circ},+2^{\circ}$, and $+3^{\circ}$, respectively, while the other two blades are kept constant. The other running parameters are the same as the former mentioned in normal condition. Figures 9 and 10 show the simulation results of the stator current and the rotor current when the pitch angle is adjusted by $+3^{\circ}$.

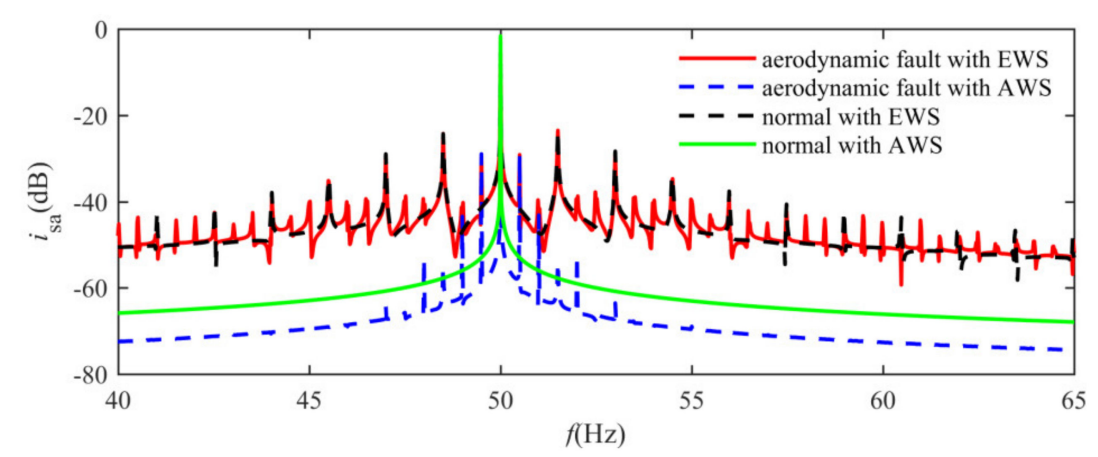

Figure 9. Stator current comparison under the aerodynamic imbalance.

Figure 9 shows the analysis results of the stator current PSD. In Figure 9, the comparison of four simulation results is given, including the aerodynamic imbalance under the EWS, the aerodynamic imbalance under the AWS, the normal operation under the EWS and the normal operation under the AWS.

It can be seen from Figure 9 that, on the condition of the aerodynamic imbalance under the AWS (in blue line), the fault harmonic frequencies in the stator current are mainly 49.5 and $50.5 \mathrm{~Hz}$. That is to say, the modulation frequency is mainly the rotor rotating frequency $\mathrm{P}$. The amplitudes at the modulation frequencies of $2 \mathrm{P}, 3 \mathrm{P}, 4 \mathrm{P}, 5 \mathrm{P}$, and $6 \mathrm{P}$ are relatively small and the other frequencies are not observed in the figure. However, on the condition of aerodynamic imbalance under the EWS (in red line), the main modulation frequencies in the stator current are $3 \mathrm{P}(1.5 \mathrm{~Hz}), 6 \mathrm{P}(3 \mathrm{~Hz}) \ldots 3 k \mathrm{P}$ in addition to $\mathrm{P}$. The modulation frequencies such as $2 \mathrm{P}, 4 \mathrm{P}, 5 \mathrm{P}, 7 \mathrm{P}, 8 \mathrm{P}$, etc. also can be observed, however their amplitudes are relatively small compared with those of the main modulation frequencies. On the normal condition under EWS (in black line), there are only the modulation frequencies of $3 k \mathrm{P}$, and on the normal condition under AWS (in green line), there is not harmonic frequency except the fundamental frequency of the stator current.

Figure 10 shows a comparison of DFIG rotor current under the four simulation conditions as mentioned above. It can be seen that, on the condition of the aerodynamic imbalance under the AWS, the harmonic frequencies of the rotor current are mainly 9.5 and $10.5 \mathrm{~Hz}$, i.e., the modulation frequency is P. On the condition of aerodynamic imbalance under the EWS, the main modulation frequencies of the rotor current include $3 \mathrm{P}(1.5 \mathrm{~Hz}), 6 \mathrm{P}(3 \mathrm{~Hz}) \ldots 3 \mathrm{kP}$ in addition to $\mathrm{P}$. The modulation frequencies of $2 \mathrm{P}, 4 \mathrm{P}, 5 \mathrm{P}, 7 \mathrm{P}, 8 \mathrm{P}$, etc. can also be observed.

However, unlike the stator current, the main harmonic amplitudes in the rotor current are relatively high. On the condition of aerodynamic imbalance under EWS, the maximum harmonic amplitude (at $51.5 \mathrm{~Hz}$ ) in the stator current is about 0.0044 p.u., which is about $0.66 \%$ of the fundamental amplitude. However, the maximum harmonic amplitude (at $8.5 \mathrm{~Hz}$ ) in rotor current is about 0.036 p.u., which is about $5.7 \%$ of the fundamental amplitude. In the PSD spectrum of Figure 10, the harmonics amplitudes with the modulation frequencies of $\mathrm{P}$ and $3 k \mathrm{P}$ are higher than those of the stator current in Figure 9. The maximum harmonic at $f+3 \mathrm{P}$ is $-23.56 \mathrm{~dB}$ in Figure 9 , and the maximum amplitude at $s f-3 \mathrm{P}$ is $-16.51 \mathrm{~dB}$ in Figure 10. The comparison data is shown in Table 2. Consequently, the harmonic 
performance in rotor current is more obvious than that of the stator current on the aerodynamic fault condition.

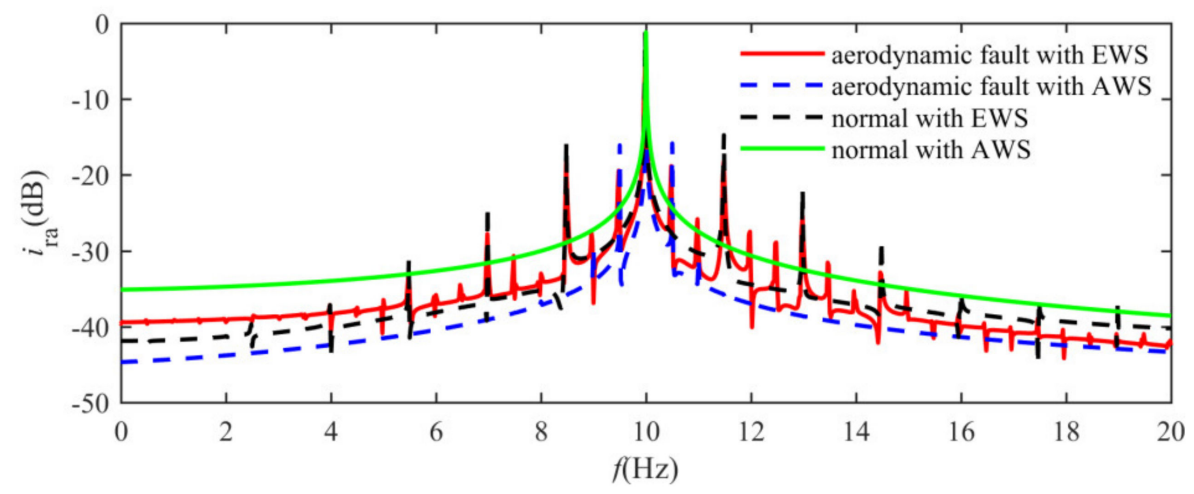

Figure 10. Rotor current comparison under the aerodynamic imbalance.

Table 2. Harmonic amplitude comparison between stator and rotor current.

\begin{tabular}{ccc}
\hline Current & $\begin{array}{c}\text { Ratio of the Maximum Harmonic } \\
\text { to the Fundamental Amplitude }\end{array}$ & $\begin{array}{c}\text { Maximum Harmonic Amplitude } \\
\text { in PSD (dB) }\end{array}$ \\
\hline stator current & $0.66 \%$ & -23.56 \\
rotor current & $5.7 \%$ & -16.51 \\
\hline
\end{tabular}

Figure 11 shows a comparison of the stator current PSD for three degrees of aerodynamic imbalance under EWS. It can be seen from the figure that the curves under the three imbalance degrees are basically consistent. The main difference is that the amplitude at the frequency $f \pm \mathrm{P}$ increases as the imbalance degree increases. However, the amplitudes at the frequency $f \pm 3 k \mathrm{P}$ do not change much, mainly because they are caused by the effects of wind shear and tower shadow, and less affected by the aerodynamic imbalance. The rotor current comparison has the similar characteristic as the stator current under the three imbalance degrees.

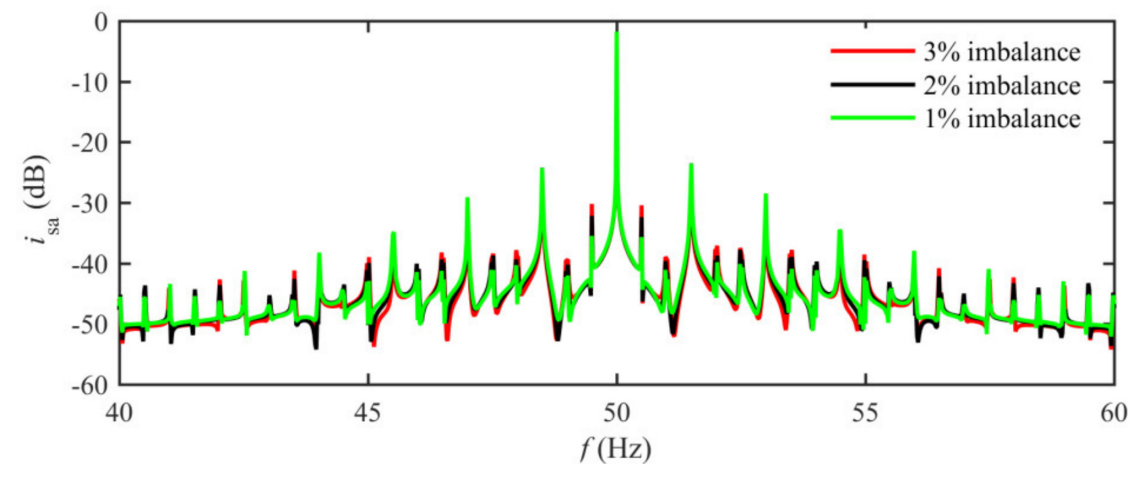

Figure 11. Stator current comparison for three aerodynamic imbalance degrees.

\subsection{Stator Winding Asymmetry Simulation}

Through the rotor aerodynamic imbalance fault simulation, the influence of the EWS on the mechanical fault characteristics of the WT is analyzed. Next, in order to analyze the influence on the electrical fault characteristics, the DFIG stator winding asymmetry fault is simulated.

The stator winding asymmetry has been simulated by means of an additional resistor connected in series with one stator phase winding and equal to the rated phase resistance $R \mathrm{~s}$, and the resistances of the other two phases remain unchanged. Then the simulations under the two kinds of wind speed 
are respectively performed, which are the stator winding asymmetrical faults under the EWS and the conventional AWS. The simulation results are shown in Figures 12 and 13 below.

In Figure 12, the stator current PSD comparison of four cases is shown, including stator winding asymmetry fault under EWS, stator winding asymmetry fault under AWS, normal operation under EWS and normal operation under AWS. Figure 12a shows the result of the stator current PSD with frequency in the range of 0-300 Hz. But since the harmonic frequencies are not clear in this figure, the partial enlargement views of stator currents PSD are shown in Figure $12 b, c$ with frequency ranges of $0-100 \mathrm{~Hz}$ and $120-180 \mathrm{~Hz}$ respectively.

There are two characteristics in the stator current PSD. Firstly, there is a clear difference between the fault and the normal condition, i.e., the odd-numbered harmonic frequencies of $150 \mathrm{~Hz}, 250 \mathrm{~Hz}$, etc. exist in the stator current under the winding asymmetry fault, which is consistent with the theoretical analysis as mentioned above. Although only the fault frequencies of $150 \mathrm{~Hz}$ and $250 \mathrm{~Hz}$ are given in Figure 12a, there are other odd-numbered harmonic frequencies, which are not given because their amplitudes are relatively small. However, there are not these fault harmonics on the normal conditions. Secondly, there exists distinct difference between EWS and AWS on the condition of stator winding asymmetry fault. In the case of winding asymmetry fault with EWS, there are harmonics with modulation frequency of $3 \mathrm{kP}$ on both sides of the odd-numbered frequencies, while no such harmonics appear around the odd-numbered frequencies under stator winding asymmetry fault with AWS.

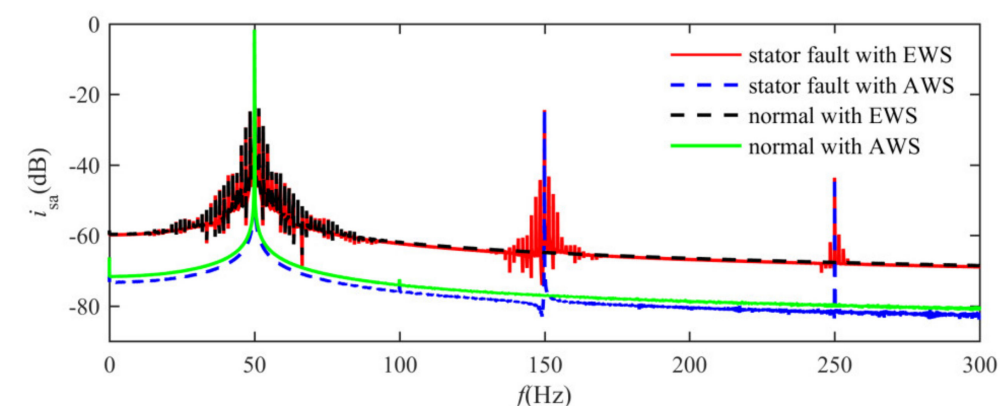

(a)

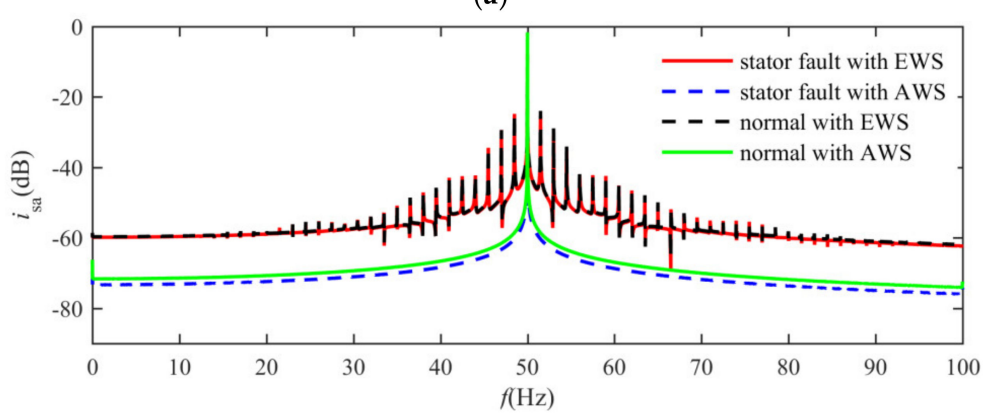

(b)

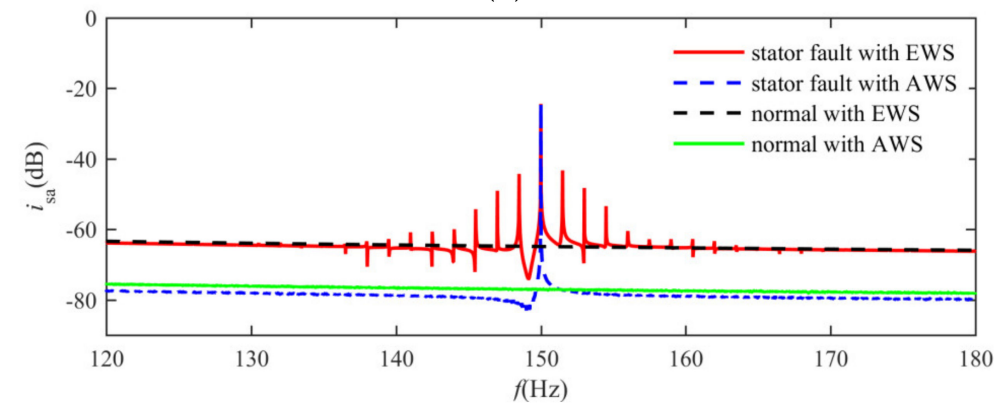

(c)

Figure 12. Stator current comparison under the stator winding asymmetry: (a) PSD of the stator current from 0 to $300 \mathrm{~Hz}$; (b) PSD of the stator current from 0 to $100 \mathrm{~Hz}$; (c) PSD of the stator current from 120 to $180 \mathrm{~Hz}$. 
Figure 13 shows the rotor current PSD comparison of the four cases as mentioned above. Figure 13a is the result of the rotor current PSD with the frequency in the range of 0 to $220 \mathrm{~Hz}$. Figure 13b,c shows the partial enlargement views of the rotor current PSD with the frequency from 0 to $30 \mathrm{~Hz}$ and 80 to $120 \mathrm{~Hz}$ respectively.

The fault characteristic in the rotor current is basically the same as the stator current. From Figure 13a, it can be seen that the fault frequencies $90 \mathrm{~Hz}, 110 \mathrm{~Hz}, 190 \mathrm{~Hz}, 210 \mathrm{~Hz} \ldots(2 k \pm s) f(f$ is $50 \mathrm{~Hz}$, and $s$ is the slip ratio of -0.2 ) appear in the rotor current in the case of stator winding asymmetry fault except for the fundamental frequency of $10 \mathrm{~Hz}$. However, there are not these fault frequencies under the normal conditions. In addition, it also can be seen from Figure 13 that there are harmonics with modulation frequency of $3 \mathrm{kP}$ on both sides of the fundamental frequency and the fault frequencies $(2 k \pm s) f$ in the case of stator winding asymmetry fault with EWS. However, in the case of stator winding asymmetry with AWS, these modulation harmonics do not appear, and there are only fundamental frequency and the fault frequencies of $(2 k \pm s) f$.

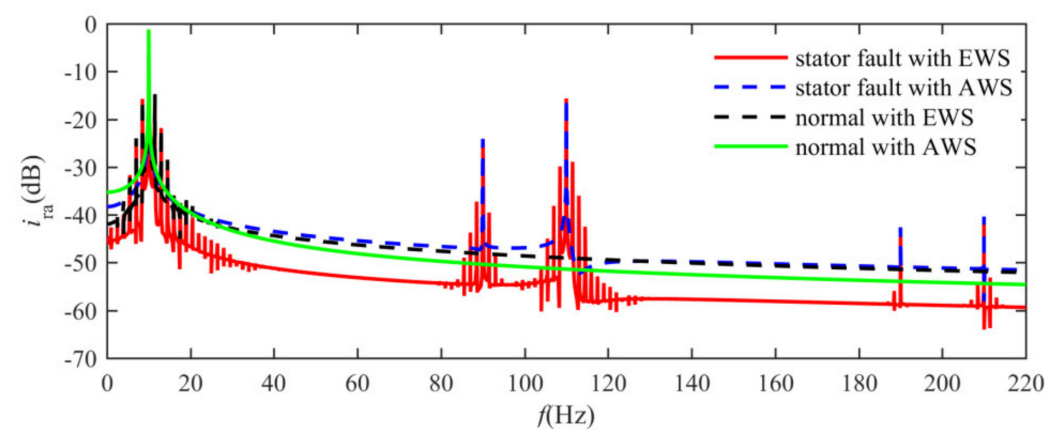

(a)

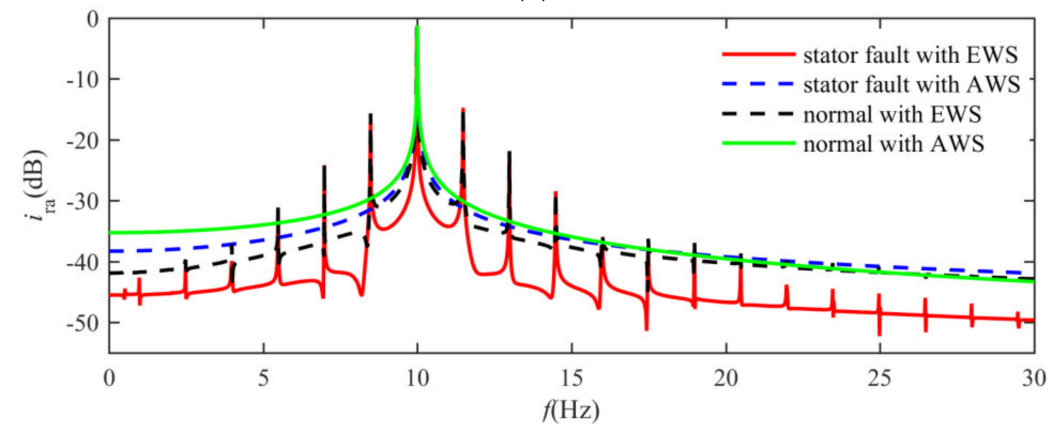

(b)

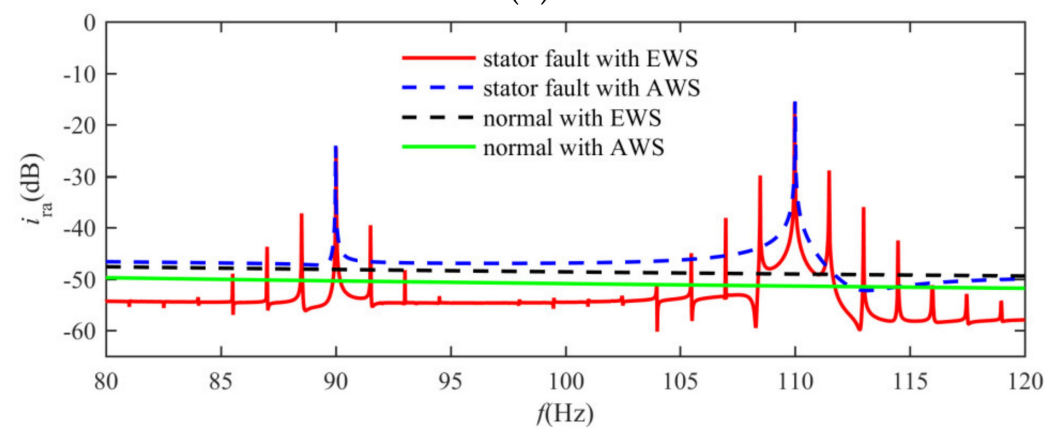

(c)

Figure 13. Rotor current comparison under the stator winding asymmetry: (a) PSD of the rotor current from 0 to $220 \mathrm{~Hz}$; (b) PSD of the rotor current from 0 to $30 \mathrm{~Hz}$; (c) PSD of the rotor current from 80 to $120 \mathrm{~Hz}$. 


\section{Discussion}

According to the analysis above mentioned, both the mechanical torque and the rotating speed of WT include the periodic fluctuation with the frequencies of $3 k \mathrm{P}(\mathrm{P}$ is the rotor rotating frequency, $k$ stands for positive integer) due to the effects of wind shear and tower shadow. Two typical mechanical and electrical faults under the EWS and the AWS are mainly studied, and the comparison analysis results are as follows:

Comparison results of the rotor aerodynamic imbalance simulation: in the case of AWS, the fault modulation frequency in stator and rotor currents is mainly P; and in the case of EWS, the fault modulation frequencies in stator and rotor currents are mainly $\mathrm{P}$ and $3 k \mathrm{P}$. In addition, there exists frequency modulation between $\mathrm{P}$ and $3 \mathrm{kP}$. The harmonic performance in rotor current is more obvious than that of the stator current on the aerodynamic fault condition.

Comparison results of the stator winding asymmetrical fault simulation: in the case of AWS, the fault frequency in the stator current is mainly $k_{1} f\left(k_{1}\right.$ stands for odd number, $f$ is the grid frequency), and the fault frequency in the rotor current is $\left(2 k_{2} \pm s\right) f$ ( $k_{2}$ stands for positive integer); while, in the case of EWS, the fault frequencies in the stator current include $k_{1} f \pm 3 \mathrm{kP}$ and $k_{1} f$, and the fault frequencies in the rotor current include $\left(2 k_{2} \pm s\right) f \pm 3 k \mathrm{P}$ and $\left(2 k_{2} \pm s\right) f$. Similarly, the harmonic performance in rotor current is more obvious than that of the stator current.

\section{Conclusions}

As wind turbines become large-scale, even small changes in wind speed or wind direction on the rotor disk area may cause large fluctuations in aerodynamic load and mechanical torque, and further affect the operation and the fault characteristics of the WTGS. Therefore, it is important to study the distribution of the actual wind speed and then analyze the fault characteristics all over again considering the spatiotemporal distribution of actual wind speed. This paper analyzed the new characteristics of mechanical and electrical fault of WTGS with DFIG based on the EWS model, and obtained some useful conclusions. In the future, the other kinds of faults of DFIG or the faults of the other kinds of WTGS can be analyzed similarly. The research results are of great significance to improve the fault diagnosis accuracy and the fault monitoring level of WTGS.

Author Contributions: Investigation, Writing and editing, X.S.; Data curation, K.C.; Software, data analysis, X.W.; Visualization and supervision, S.W. All authors have read and agreed to the published version of the manuscript.

Funding: This research was funded by National Natural Science Foundation of China, No.51777075, Natural Science Foundation of Hebei Province, No.E2019502064, and the Fundamental Research Funds for the Central Universities, No.2018MS121.

Conflicts of Interest: The authors declare no conflict of interest.

\section{Acronyms}

$\begin{array}{ll}\text { WT } & \text { wind turbines } \\ \text { DFIG } & \text { doubly-fed induction generator } \\ \text { WTGS } & \text { wind turbine generator system } \\ \text { AWS } & \text { average wind speed at the hub center } \\ \text { EWS } & \text { equivalent wind speed } \\ \text { MCSA } & \text { motor current signature analysis } \\ \text { PSD } & \text { power spectral density } \\ \text { FFT } & \text { fast Fourier transform }\end{array}$




\section{Appendix A}

The computation process of the rotor current in Equation (15) is shown as follows:

$$
\begin{aligned}
i_{\mathrm{ra}} & =I_{\mathrm{r}} \cos \left(\int_{0}^{t} \omega_{z} d \tau\right) \\
& =I_{\mathrm{r}} \cos \left\{\int_{0}^{t}\left[\omega_{z 0}-\frac{n_{p}}{J} \sum_{k=1}^{n+1} \frac{T_{k}}{\omega_{k}} \sin \left(\omega_{k} \tau\right)\right] d \tau\right\} \\
& =I_{\mathrm{r}} \cos \left[\omega_{z 0} t+\sum_{k=1}^{n+1} \frac{n_{p} T_{k}}{J \omega_{k}^{2}} \cos \left(\omega_{k} t\right)\right] \\
& =I_{\mathrm{r}}\left\{\cos \left(\omega_{z 0} t\right) \cos \left[\sum_{k=1}^{n+1} W_{k} \cos \left(\omega_{k} t\right)\right]-\sin \left(\omega_{z 0} t\right) \sin \left[\sum_{k=1}^{n+1} W_{k} \cos \left(\omega_{k} t\right)\right]\right\} \\
& \approx I_{\mathrm{r}}\left\{\cos \left(\omega_{z 0} t\right)-\sin \left(\omega_{z 0} t\right)\left[\sum_{k=1}^{n+1} W_{k} \cos \left(\omega_{k} t\right)\right]\right\} \\
& =I_{\mathrm{r}} \cos \left(\omega_{z 0} t\right)-\sum_{k=1}^{n+1} I_{\mathrm{r}} W_{k} \sin \left(\omega_{z 0} t\right) \cos \left(\omega_{k} t\right) \\
& =I_{\mathrm{r}} \cos \left(\omega_{z 0} t\right)-\sum_{k=1}^{n+1} \frac{I_{\mathrm{r}} W_{k}}{2}\left[\sin \left(\omega_{z 0} t+\omega_{k} t\right)+\sin \left(\omega_{z 0} t-\omega_{k} t\right)\right] \\
& =I_{\mathrm{r}} \cos \left(\omega_{z 0} t\right)-\sum_{k=1}^{n} I_{k} \sin \left(\omega_{z 0} t+3 k \omega_{\mathrm{w}} t\right)-\sum_{k=1}^{n} I_{k} \sin \left(\omega_{z 0} t-3 k \omega_{\mathrm{w}} t\right)-I_{\mathrm{r} 1} \sin \left(\omega_{z 0} t+\omega_{\mathrm{w}} t\right)-I_{\mathrm{r} 1} \sin \left(\omega_{z 0} t-\omega_{\mathrm{w}} t\right)
\end{aligned}
$$

where $W_{k}=n_{\mathrm{p}} T_{k} / J\left(\omega_{k}\right)^{2}$.

\section{References}

1. Cem, E.; Tugce, C. In case study: Investigation of tower shadow disturbance and wind shear variations effects on energy production, wind speed and power characteristics. Sustain. Energy Technol. Assess 2019, 35, 148-159.

2. Wang, H.; Zhang, B.; Qiu, Q. Numerical study of the effects of wind shear coefficients on the flow characteristics of the near wake of a wind turbine blade. Proc. Inst. Mech. Eng. Part A 2016, 230, 86-98. [CrossRef]

3. Nilay, S.U.; Oguz, U. Effect of steady and transient wind shear on the wake structure and performance of a horizontal axis wind turbine rotor. Wind Energy 2013, 16, 1-17.

4. Houtzager, I.; van Wingerden, J.W.; Verhaegen, M. Wind turbine load reduction by rejecting the periodic load disturbances. Wind Energy 2013, 16, 235-256. [CrossRef]

5. Wen, B.; Wei, S.; Wei, K.; Yang, W.; Peng, Z.; Chu, F. Power fluctuation and power loss of wind turbines due to wind shear and tower shadow. Front. Mech. Eng. 2017, 12, 321-332. [CrossRef]

6. Wen, B.; Wei, S.; Wei, K.; Yang, W.; Peng, Z.; Chu, F. Influences of wind shear and tower shadow on the power output of wind turbine. J. Mech. Eng. 2018, 54, 124-132. [CrossRef]

7. Tan, J.; Hu, W.H.; Wang, X.R.; Chen, Z. Effect of tower shadow and wind shear in a wind farm on AC tie-line power oscillations of interconnected power systems. Energies 2013, 6, 6352-6372. [CrossRef]

8. Wan, S.T.; Cheng, K.R.; Sheng, X.L.; Wang, X. Characteristic analysis of DFIG wind turbine under blade mass imbalance fault in view of wind speed spatiotemporal distribution. Energies 2019, 12, 3178. [CrossRef]

9. Milad, F.; Asghar, A.F. Recognition and assessment of different factors which affect flicker in wind turbines. IET Renew. Power Gen. 2016, 10, 250-259.

10. Miao, F.L.; Shi, H.S.; Zhang, X.Q. Impact of the converter control strategies on the drive train of wind turbine during voltage dips. Energies 2015, 8, 11452-11469. [CrossRef]

11. Zhao, M.H.; Jiang, D.X.; Li, S.H. Research on fault mechanism of icing of wind turbine blades. In Proceedings of the World Non-Grid-Connected Wind Power and Energy Conference, Nanjing, China, 24-26 September 2009; pp. 356-359.

12. Niebsch, J.; Ramlau, R.; Thien, T.N. Mass and aerodynamic imbalance estimates of wind turbines. Energies 2010, 3, 696-710. [CrossRef]

13. Sheng, X.L.; Wan, S.T.; Cheng, L.F.; Li, Y.G. Blade aerodynamic asymmetry fault analysis and diagnosis of wind turbines with doubly fed induction generator. J. Mech. Sci. Technol. 2017, 31, 5011-5020. [CrossRef]

14. Xiang, G.; Wei, Q. Imbalance fault detection of direct-drive wind turbines using generator current signals. IEEE Trans. Energy Convers. 2012, 27, 468-476. 
15. Estefania, A.; Andres, H.E.; Emilio, G.L. Current signature analysis to monitor DFIG wind turbine generators: A case study. Renew. Energy 2018, 116, 5-14.

16. Stefani, A.; Yazidi, A.; Rossi, C.; Filippetti, F.; Casadei, D.; Capolion, G.A. Doubly fed induction machines diagnosis based on signature analysis of rotor modulating signals. IEEE Trans. Ind. Appl. 2008, 44, 1711-1721. [CrossRef]

17. Casadei, D.; Filippetti, F.; Rossi, C.; Stefani, A. Closed loop bandwidth impact on doubly fed induction machine asymmetries detection based on rotor voltage signature analysis. In Proceedings of the 2008 43rd International Universities Power Engineering Conference, Padova, Italy, 1-4 September 2008; pp. 1-5.

18. Dai, Z.J. Research and Implementation of Fault Diagnosis for Stator and Rotor of Doubly-Fed Induction Generator Based on Improved HHT. Master's Thesis, Shanghai Electric Institute, Shanghai, China, 2015.

19. Williamson, S.; Djurović, S. Origins of stator current spectra in DFIGs with winding faults and excitation asymmetries. In Proceedings of the 2009 IEEE International Electric Machines and Drives Conference, Miami, FL, USA, 3-6 May 2009; pp. 563-570.

20. Gritli, Y.; Zarri, L.; Rossi, C.; Filippetti, F.; Capolino, G.A.; Casadei, D. Advanced diagnosis of electrical faults in wound-rotor induction machines. IEEE Trans. Ind. Electron. 2013, 60, 4012-4024. [CrossRef]

21. Wan, S.T.; Cheng, L.F.; Sheng, X.L. Effects of yaw error on wind turbine running characteristics based on the equivalent wind speed model. Energies 2015, 8, 6286-6301. [CrossRef]

22. Wan, S.T.; Cheng, L.F.; Sheng, X.L. Numerical analysis of the spatial distribution of equivalent wind speed in large-scale wind turbines. J. Mech. Sci. Technol. 2017, 31, 965-974. [CrossRef]

23. Dolan, D.S.L.; Lehn, P.W. Simulation model of wind turbine $3 p$ torque oscillations due to wind shear and tower shadow. IEEE Trans. Energy Convers. 2006, 21, 717-724. [CrossRef]

24. De Kooning, J.D.M.; Vandoorn, T.L.; De Vyver, V.J.; Meersman, B.; Vandevelde, L. Shaft speed ripples in wind turbines caused by tower shadow and wind shear. IET Renew. Power Gen. 2014, 8, 195-202. [CrossRef]

25. Kong, Y.G.; Wang, J.; Gu, H.; Wang, Z.X.; Xu, D.L. Dynamic modeling of wind turbine wind speed based on wind shear and tower shadow effect. Acta Energ. Sol. Sin. 2011, 32, 1237-1244.

26. He, Y.K.; Hu, J.B.; Xu, L. Operation Control of Grid Doubly-Fed Induction Generator, 2nd ed.; Electric Power Press: Beijing, China, 2014; pp. 52-54.

27. Sheng, X.L.; Wan, S.T.; Cheng, L.F.; Li, Y.G. Characteristics analysis of DFIG under the blade mass imbalance fault. Acta Energ. Sol. Sin. 2017, 38, 1324-1332. 